\title{
Study on properties of carbon fibre reinforced cement-based grouting materials
}

\author{
Xin-e Yan $^{1, *}$ \\ ${ }^{1}$ School of civil engineering, Xi'an traffic engineering institute, $710065 \mathrm{Xi}$ 'an, China
}

\begin{abstract}
As an efficient, eco-friendly and economical solution for connecting precast concrete components, grouted sleeve connectors aroused widespread interest in engineering site. However, as the key material of grouted sleeve connection, grouting material needs to provide enough good performance to meet the engineering requirements. In order to better design the mix proportion of grouting materials, this paper studies the influence of water binder ratio, carbon fibre content, expansion agent addition and other factors on the performance of grouting materials, and optimizes the mixture ratio of grouting materials by analyzing the workability, compressive strength and expansibility, and analyzes the bonding performance of grouting materials by using the half-grouting steel sleeve connector.
\end{abstract}

\section{Introduction}

With the development of building, materials and information technology, many new environmentally friendly structural systems are emerging ${ }^{[1]}$. The development of prefabricated concrete structure meets the needs of transformation and upgrading of traditional construction industry, and is one of the important directions of future building structure ${ }^{[2-4]}$.

In the prefabricated concrete frame structure, the connection mode of column, beam and floor, especially the connection mode of beam-column joint, is the fundamental to distinguish the assembled structure from the cast-in-place structure, and it is also the core stress part that affects the seismic performance of the whole structure ${ }^{[5-6]}$. However, the joint area of prefabricated concrete frame structure is its weak link, especially the connection of beam-column joint directly affects the stability and seismic performance of the whole structure. Therefore, it is of great significance to ensure the good mechanical properties of the joint area of prefabricated frame structure for the safety of the whole structure ${ }^{[7]}$.

As the key technology of prefabricated structure, the longitudinal reinforcement of prefabricated components is usually connected by sleeve grouting, and the reinforcement transmits force through the joint action of grouting material and sleeve ${ }^{[8]}$. The reliability of grouting sleeve connection mainly depends on the performance of grouting material. Sleeve grouting material should not only have excellent physical and mechanical properties, but also have good working performance ${ }^{[9]}$. Cement-based grouting material is widely used in practical engineering because of its simple preparation, easy use, good stability and durability. However, there are still some problems such as low bond strength, too fast setting time, low strength in later stage, and hardening shrinkage ${ }^{[10]}$. In view of these problems, scholars have done a lot of research on the performance of grouting materials. Yahia et al. [11] have researched the relevant significance of each of the high-range water-reducer, antiwashout admixtures, and W/C on fluidity, stability, and residual compressive strength. The results show that the influence of water binder ratio on the flow and mechanical properties of grouting materials. was significantly higher than that of water reducing agent and stabilizer. The compressive strength of grouting materials within the range of water binder ratio was predicted accurately by the first-order linear model. Khayat et al. ${ }^{[12]}$ have made a great contribution to the development and application of grouting materials. They established the yield stress model of high performance grouting materials by mathematical means, and studied the flow performance of cement-based grouting materials through a variety of tests. Shannag et al. [13] have researched a high performance cement-based grouting material with good fluidity, strength and durability by adding natural pozzolan and silica fume into the grouting material. The test results show that the $28 \mathrm{~d}$ strength of the grouting material with appropriate proportion of pozzolan and silica fume is more than 90Mpa. Lim et al. ${ }^{[14]}$ have studied the consistency and strength properties of cement grouts prepared with three different sand grading. Based on the flowing time, the results indicated that the finer sand grading had worse flowability than those of the coarser sand grading. This shows that in order to obtain better workability, it is necessary to reduce the fine sand content and increase the water to cement ratio. When the water binder ratio was $0.61-0.63,7 \mathrm{~d}$ and $28 \mathrm{~d}$ compressive strengths of specimen with the coarser sand grading was higher than that of the finer sand grading. However, when $0.65-0.7$ water to cement ratio was

\footnotetext{
* Corresponding author: yanxine@126.com
} 
adopted, the higher flexural, splitting tensile strengths and long-term compressive were obtained for the finer sand grading specimen than that of the specimen with coarser sand grading.

At present, there are many researches on the performance of cement-based grouting materials at home and abroad, but few researches on the use of carbon fibre reinforced reactive powder concrete as grouting materials. Whether carbon fibre can improve the connection between reinforcement and grouting material needs further research. This paper introduced a cementbased grouting material and investigated the effects of the content of carbon fibre on the workability and bond performance.

\section{Materials and methods}

\subsection{Materials and mix proportions}

The preparation method of reactive powder concrete (RPC) has be used as a prospective grouting material [15], contains Grade 52.5 (Chinese cement grading system) Portland cement made in Shaanxi Province, China; silica fume (SF), quartz powder (QP), quartz sand (QS), a superplasticizer (SP) and chopped carbon fibre (CF) as a substitute for steel fibre. The mix design of the RPC grouting material is also shown in Table 1. As informed by the supplier, the chopped carbon fibre with a diameter of $7.3 \mu \mathrm{m}$ and a length of $5 \mathrm{~mm}$ were used in this work, whose elastic modulus is $231 \mathrm{GPa}$, tensile strength is $4558 \mathrm{MPa}$, elongation at break is $2.05 \%$, and density is $1820 \mathrm{~kg} / \mathrm{m} 3$. In order to achieve a good dispersion for carbon fibre in the grout material, hydroxypropyl methylcellulose (HPMC) as the dispersing agent and AGITAN P803 as the antifoaming agent were employed. Sulphoaluminate expansion agent (SEA) bought from the building materials market is used to improve the expansion performance.

Three factors, Water-binder ratio (W/B) (by weight), CFs volume in one cubic meter RPC and SEA content (by weight), were considered in this study. The mix proportions used in this study are listed in Table 1.

Table 1. Mixture proportions of grouting material

\begin{tabular}{|c|c|c|c|c|c|c|c|}
\hline Cement & SF & QP & QS & SP & W/B & CF & EA \\
\hline 1 & 0.35 & 2.5 & 1.1 & 0.2 & $\begin{array}{c}0.16- \\
0.26\end{array}$ & $\begin{array}{c}0- \\
0.8 \%\end{array}$ & $\begin{array}{c}0- \\
5 \%\end{array}$ \\
\hline
\end{tabular}

\subsection{Sample preparation for strength tests}

An electric mixer with a $0.35 \mathrm{~m}^{3}$ capacity was used for mixing the concrete ingredients. Based on literature reports, obtaining high performance RPC grouting material requires a specially designed mixing procedure. First, dry components consisting of Portland cement, silica fume, silica sand and quartz powder were mixed slowly for approximately $7 \mathrm{~min}$. Second, the superplasticizer, Sulphoaluminate expansion agent and CFs dispersion solution were added into water and the entire mixture was immediately added to the ingredients. The mixture was then stirred at a gradually rising speed for about $10 \mathrm{~min}$.

The workability, compressive strength and vertical expansion rate of grouting materials were measured according to the methods specified in GB/T 50448-2015. The technical specifications of the sleeve grouting material are shown in Table 2.

Table 2 Technical specifications of the sleeve grouting material

\begin{tabular}{|c|c|c|}
\hline \multirow{2}{*}{$\begin{array}{c}\text { Workability } \\
(\mathrm{mm})\end{array}$} & Initial & $\geq 300$ \\
\cline { 2 - 3 } & $30 \mathrm{~min}$ & $\geq 260$ \\
\hline \multirow{2}{*}{$\begin{array}{c}\text { Compressive } \\
\text { strength } \\
(\mathrm{MPa})\end{array}$} & $3 \mathrm{~d}$ & $\geq 35$ \\
\cline { 2 - 3 } & $28 \mathrm{~d}$ & $\geq 85$ \\
\hline \multirow{2}{*}{$\begin{array}{c}\text { Expansion } \\
(\%)\end{array}$} & $3 \mathrm{~h}$ & $\geq 0.02$ \\
\cline { 2 - 3 } & $24 \mathrm{~h}-3 \mathrm{~h}$ & $0.02-0.05$ \\
\hline
\end{tabular}

Commercial half-grouted sleeves and the rebar with $16 \mathrm{~mm}$ diameter are used in this work. In steel sleeve connector, a rebar with a straight thread end needs to screw into the threaded end of the sleeve at first. And then, threaded bars are installed in the sleeves by a pipe wrench. The bond length between rebar and sleeve is 8 times of the diameter of rebar. The grout material is filled into the sleeve from the grout hole by a grout pump. Details of the half grout sleeve connections are shown in Fig. 1. In order to test the bond stress-slip response of the specimens, the tension loading experiments of the connection specimens were carried out by an electro-hydraulic servo testing machine. All specimens are loaded with a tensile speed of $0.5 \mathrm{kN} / \mathrm{s}$.

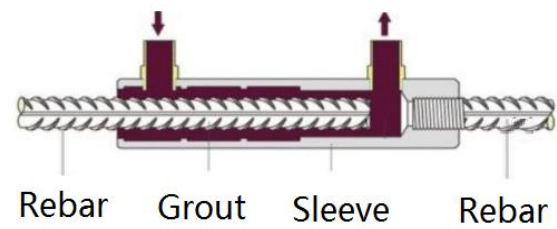

Fig.1. Schematic of the grouted sleeve connection

\section{Results and discussion}

\subsection{Influence of different fit ratio on grouting material performance}

\subsubsection{W/B}

$\mathrm{W} / \mathrm{B}$ is one of the key factors affecting the properties of cement-based materials. Fig.2 shows the effects of W/B on the performance of grouting material, including 
workability, compressive strength and expansion. With the increase of water binder ratio, the initial workability of grouting materials gradually increases. After 30 minutes, compared with the initial fluidity, the workability of grouting materials was found decrease significantly under the corresponding $\mathrm{W} / \mathrm{B}$, but also increased with the increase of W/B. Fig.2 (b) shows the compressive strength of grouting materials under different W/B. A clear trend was seen that the compressive strength of grouting material is significantly improved with the extension of curing age. However, with the increase of water binder ratio, the compressive strength of grouting materials first increased and then decreased. It is necessary for a good grouting material to have micro expansion performance. With the increase of water consumption of grouting material, its expansibility first increases and then decreases. Obviously, too much water being employed reduces the expansion of grouting materials.
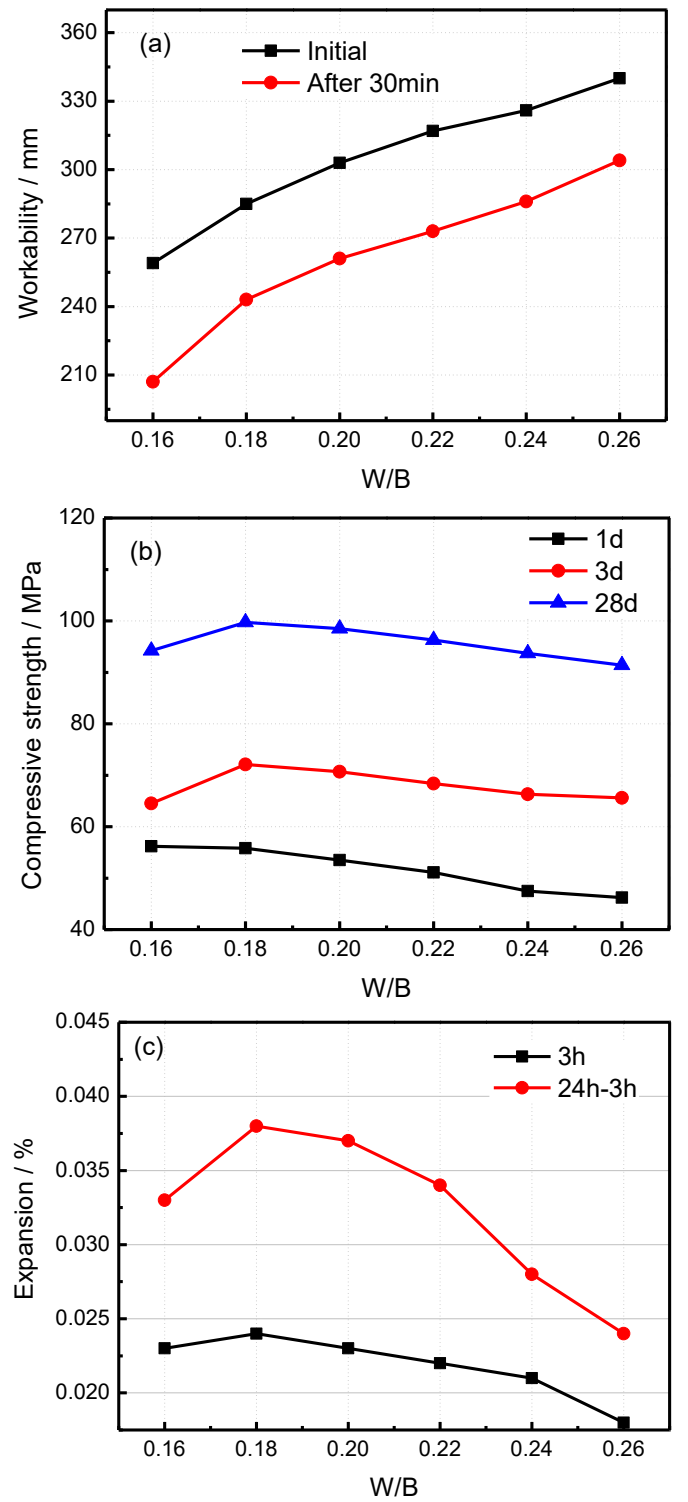

Fig. 2. Influence of different water-binder ratio on grouting material performance (a) workability under initial time and after 30 minutes; (b) compressive strength under different curing days; (c) expansion rate under $3 \mathrm{~h}$ and $24 \mathrm{~h}$.
The increase of water use in the preparation of cement-based materials will inevitably increase the fluidity of the materials, but water is also wrapped in the bulk structure of the materials [16]. When the water is consumed by chemical and physical actions, the pore structure will be formed in the bulk phase of the material, which will lead to the deterioration of the mechanical properties of the material. Therefore, in order to ensure that the grouting material has good workability and high compressive strength, appropriate water employing must be considered. Based on the influence of water binder ratio on the performance of grouting materials, a suitable range of $\mathrm{W} / \mathrm{B}$ is $0.18-0.22$.

\subsubsection{Content of CFs}

Carbon fibre is usually used as a kind of reinforcement or functional material in cement-based materials. The initial workability and $30 \mathrm{~min}$ workability of grouting material with carbon fibre can be seen in Fig. 2 (a). It can be seen that the workability of grouting material decreases when carbon fibre is added into the grouting material. When the volume content is $0.2 \%$, the initial workability decreases by $4.5 \%$, but when the volume content increases to $0.8 \%$, the initial workability decreases by $18.2 \%$. The compressive strength of grouting material added with carbon fibre after curing for $1 \mathrm{~d}, 3 \mathrm{~d}$ and $28 \mathrm{~d}$ is shown in Fig. 3. The results show that after curing for $1 \mathrm{~d}$ and $3 \mathrm{~d}$ for grouting material, the compressive strength of decreases with increase of the carbon fibre content; and curing extended to $28 \mathrm{~d}$, the compressive strength of grouting materials showed a significant increase trend, with the increase of carbon fibre content. When the volume content of carbon fibre is $0.2 \%$ in grouting material, the compressive strength reached $94.2 \mathrm{MPa}$, but when the volume content increases to $0.8 \%$, the initial workability decreases by $15.4 \%$. Fig. 3 (c) shows the effect of carbon fibre content on the expansion properties of grouting materials. It can be seen that when the content of carbon fibre reaches $0.2 \%$, the expansion performance of grouting material has little change with the increase of carbon fibre content. From the analysis of the influence of the content carbon fibre on the performance of grouting material, a small amount of carbon fibre has little effect on its workability expansion, but can improve the compressive strength of grouting material. Therefore, the amount of carbon fibre can be controlled in $0.2-0.4 \%$.

\subsubsection{Content of expansion agent}

If the expansion agent is not used in cement-based materials, it will inevitably shrink during the curing process. However, as the connecting material of grouting sleeve and steel bar, it needs to have a proper expansion to obtain the tight bonding between grouting sleeve and steel bar. The effect of the expansive agent is caused by the hydration reaction of mineral components to produce expansive ettringite. The hydration products increase with the increase of the expansion agent content, the system consistency increases and the workability 
decreases. Based on Fig.4, with the increase of expansive agent content, the expansion rate of grouting material increases significantly, but its compressive strength changes little, indicating that the expansion effect of expansive agent is significant.
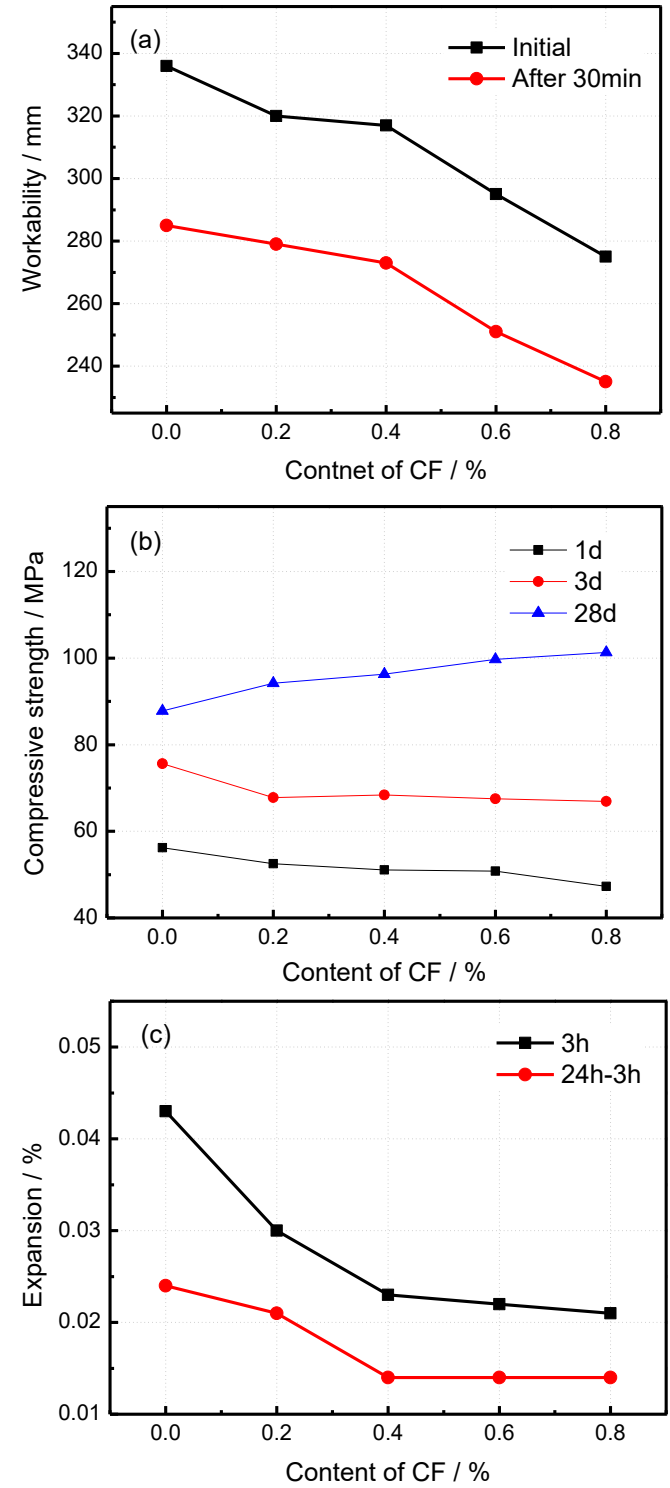

Fig. 3. Influence of different content of CF on grouting material performance (a) workability under initial time and after 30 minutes; (b) compressive strength under different curing days; (c) expansion rate under $3 \mathrm{~h}$ and $24 \mathrm{~h}$.

\subsection{Bonding properties of grouting materials}

The measured force-displacement curves of rebar and half-grouting sleeve connection specimen are shown in Fig. 5. It can be seen that the measured forcedisplacement curve of the half-grouting sleeve connection specimen is similar to that of the rebar under uniaxial tension test. This can be attributed to the expansion of the grouting material which creates an effective constraint on the sleeve, thus enhancing the force at the interface between the reber and the grouting material, resulting in the force greater than the tensile strength of the rebar. The measured force-displacement curves show a characteristic of typical tensile curve which includes four distinctive stages, containing elastic, yielding, hardening and failure stages [17]. At the initial elastic stage, a linearly elastic deformation occurred in the specimens, and the load increases rapidly with small displacement which shows the specimen have a high degree of stiffness. It can be seen that two curves almost coincide which indicates mechanical characteristics are the same. As the axial loads at approximated $89 \mathrm{kN}$, the specimen elongates rapidly and behaves plastically which is yielding stage. Subsequently, due to the high bond strength between grouting material and rebar, the specimens were yielded by the increase applied tensile load, resulting in a long linear plateau on the curve. Finally, the rebars were broken.
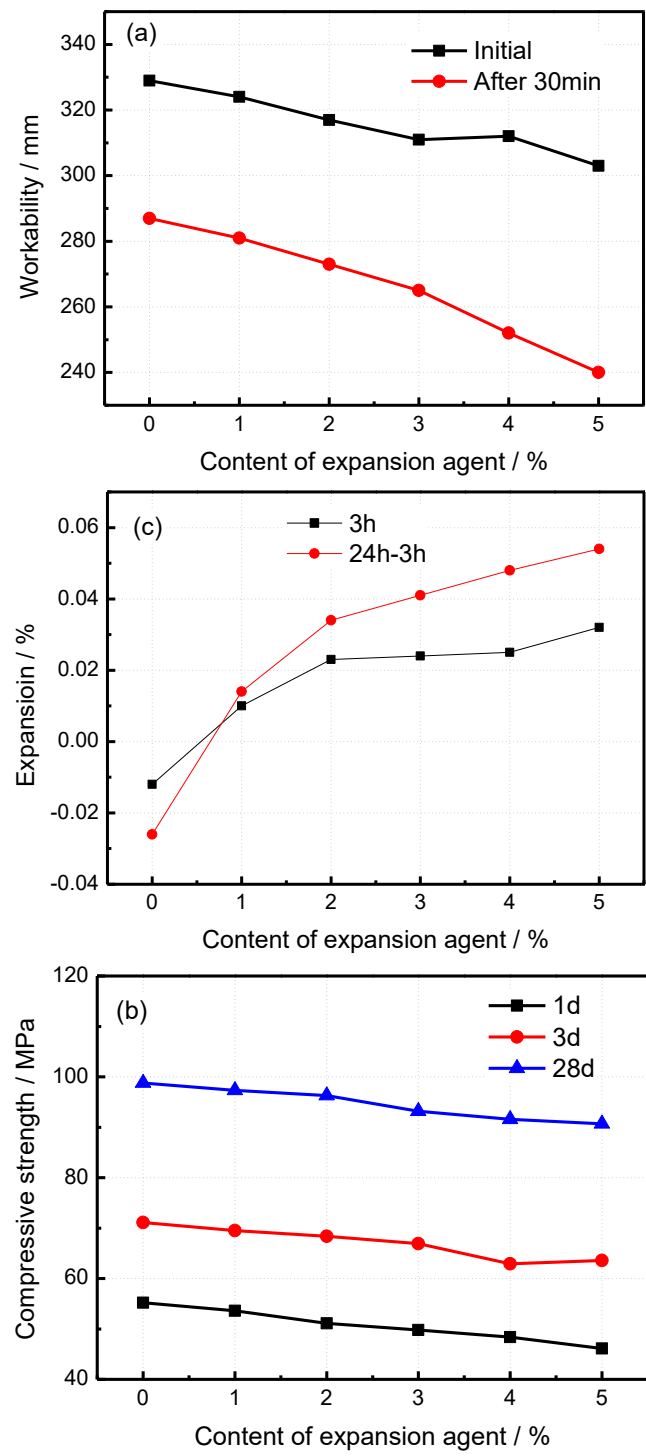

Fig. 4. Influence of different content of expansive agent on grouting material performance (a) workability under initial time and after 30 minutes; (b) compressive strength under different curing days; (c) expansion rate under $3 \mathrm{~h}$ and $24 \mathrm{~h}$. 


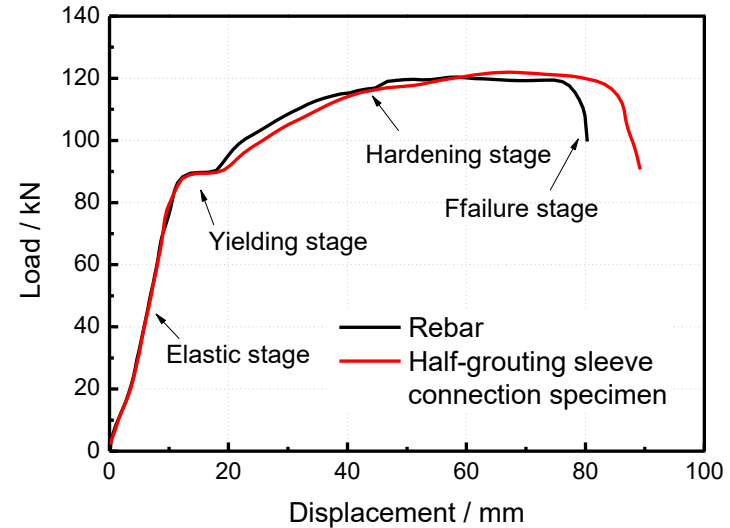

Fig. 5. Force-displacement curves for rebar and specimen under the uniaxial loading condition

\section{Conclusion}

In order to explore the performance of carbon fibre reinforced cement mixture, the cement-based mixture with different mix proportion was studied. The results show that when the water binder ratio is $0.18-0.22$, the volume content of carbon fibre is $0.2 \%-0.4 \%$, and the addition amount of expansion agent is $2 \%$, the workability, compressive strength and expansion rate of the mixture are better, which meets the national standard requirements of composite sleeve grouting material. The bonding strength of the mixed material is analyzed by the force-displacement curve of the half-grouting sleeve connection specimen. The results show that the failure of the specimen is mainly caused by the fracture of reinforcement. Therefore, the cement-based mixture can be used as grouting material for grouted sleeve connector.

\section{Acknowledgements}

This work was supported by the Scientific Research Project of Shaanxi Education Department (No. 18JK1067) and the Natural Science Research Project of Xi'an Eurasia University (2019XJZK03).

\section{References}

1. M. Faruque Hossain. Renew. Sust. Energ. Rev., 81, 3051 (2018)

2. Z Li, Y Qi, J Teng. Eng. Struct.,209, 110217 (2020)

3. A Baghdadi, M Heristchian, L Ledderose, et al. Eng. Struct., 212, 110456 (2020)

4. G Wu, R Yang, L Li, et al. J. Clean Prod., 219, 753 (2019)

5. Z Chen, J Liu, Y Yu, et al. J. Constr. Steel. Res., 139, 69 (2017)

6. A Zhang, H Zhang, Z Jiang, et al. J. Constr. Steel. Res., 164, 105771 (2020)

7. W Ferdous, Y Bai, T Duc Ngo, et al. Eng. Struct., 183, 883 (2019)
8. F Xu, K Wang, S Wang, et al. Constr. Build. Mater., 185, 264 (2018)

9. H Haider, A Hashim, N Sulong. Constr. Build. Mater., 237, 117582 (2020)

10. Z M Wang, X D Pei, L J Zhang. KEY ENG MATER, 249, 397 (2003)

11. A. Yahia, K. H. Khayat. Cem. Concr. Res., 31(5): 749 (2001)

12. A. Yahia, K. H. Khayat. Cement Concrete and Aggregates, 20(1), 145 (1998)

13. M. J. Shannag. Cem. Concr. Res., 32(5), 803 (2002)

14. S. K. Lim, C. S. Tan, K. P. Chen, L. L. Min and P. L. Wah. Constr. Build. Mater., 38(1), 348 (2013)

15. H Wang, X Gao, J Liu, et al. Constr. Build. Mater., 187, 699 (2018)

16. Y Wang, M An, Z, Yu. Constr. Build. Mater., 125, 160 (2016)

17. G Zheng, Z Kuang, J Xiao, et al. Constr. Build. Mater., 233, 117233 (2020) 